\title{
Interference competition in a planktivorous fish (Rutilus rutilus) at different prey densities and temperatures
}

\author{
Piotr Maszczyk • Maciej Bartosiewicz • \\ Jakub Eryk Jurkowski · Tomasz Wyszomirski
}

Received: 10 May 2013/ Accepted: 27 January 2014/Published online: 19 February 2014

(C) The Author(s) 2014. This article is published with open access at Springerlink.com

\begin{abstract}
The effect of interference competition can be assessed by comparing the capture rate of a predator foraging alone with that of the predator within a group. Since such an effect could be prey density dependent, a constant density of prey must be maintained while assessing this effect, irrespective of the elimination of prey by predation. However, when studying a predator-harvester, such as a planktivorous fish, which collects zooplankton at a rate of up to 1 prey s ${ }^{-1}$, instantaneous replacement of each consumed prey item is not feasible. This problem was solved in short-lasting mesocosm experiments by minute-byminute supplementation to replace eliminated Daphnia and maintain a constant average prey density. Such experiments were performed with different numbers of foraging roach (Rutilus rutilus) at three prey densities and in two
\end{abstract}

Handling Editor: Christopher Steiner.

Electronic supplementary material The online version of this article (doi:10.1007/s10201-014-0426-3) contains supplementary material, which is available to authorized users.

P. Maszczyk $(\varangle) \cdot$ M. Bartosiewicz · J. E. Jurkowski Department of Hydrobiology, Faculty of Biology, Biological and Chemical Research Centre, University of Warsaw, Żwirki i Wigury 101, 02-089 Warsaw, Poland e-mail: p.maszczyk@uw.edu.pl

Present Address:

M. Bartosiewicz

Institut National de la recherche scientifique, Centre Eau, Terre et Environnement, Quebec, Canada

T. Wyszomirski

Department of Plant Ecology and Environmental Conservation, Faculty of Biology, Biological and Chemical Research Centre, University of Warsaw, Żwirki i Wigury 101, 02-089 Warsaw, Poland ranges of ambient temperature. The number of Daphnia required at the start of each experiment to establish the initial prey density and the number that it was necessary to add per minute were determined in experiments conducted without prey supplementation and in preliminary experiments with prey supplementation. The results of this study revealed that fish foraging in a group eat less, due to both exploitation and non-aggressive competition for space. Moreover, the effect of interference competition was stronger at higher temperatures, irrespective of the prey density, indicating that natural populations of roach foraging in shoals may suffer more from competitive interactions in warmer waters.

Keywords Density dependence · Intraspecific competition - Interference competition - Feeding rate

\section{Introduction}

Interference competition occurs when direct interactions between resource-sharing competitors (congeners or conspecifics) reduce access to shared resources, leading to a decrease in the rate of utilization of those resources (Miller 1967; Hassell and Varley 1969). This decrease could be due to active (e.g., Mansour and Lipcius 1991; Cresswell 1997) or passive (e.g., Dolman 1995) interactions, the former manifested through food theft and aggressive interactions, and the latter through obstruction of access to resources to other individuals by non-aggressive behavior. In the competition for food, the effect of interference might be obscured by a reduction in the feeding rate due to food depletion (exploitative competition) by competitors. As such an effect is difficult to exclude in experiments, little effort has been made to accurately assess the quantitative 
impact of interference on the feeding rates, growth, and survival rates of competing animals, despite evidence of their importance (Schoener 1983). While most studies facing this problem have focused on demonstrating the simultaneous effect of both types of competition (e.g., MacIsaac and Gilbert 1991; Rutten et al. 2010), surprisingly, some have implicitly assumed that the effect of exploitation is negligible (e.g., Sutherland and Koene 1982; Ens and Goss-Custard 1984; Stillman et al. 2002; Nakayama and Fuiman 2010; Ping et al. 2011). However, it is clear that exploitative competition may lead to a gross overestimation of the effect of interference, since the latter phenomenon is prey density dependent (Sutherland and Koene 1982; Vahl et al. 2005).

The majority of studies that have attempted to test the effect of interference alone have approached the issue indirectly using either statistical (Scharf et al. 2008) or mathematical (Stillman et al. 2000) tools, including models based on field observations (Gyimesi et al. 2010), or a complex description of diet versus space use with measurements of both prey availability and risk of intraspecific interactions (Post et al. 1999). A simple direct measurement of the level of interference competition can only be achieved in a few specific systems where competition is coupled with the excretion of allelochemicals: toxins or growth inhibitors (Steinwascher 1978; Folt and Goldman 1981). In such systems, to distinguish the effects of both types of competition, the experiments must be performed at the same prey density but in the presence of different concentrations of chemicals from congeners or conspecifics. Otherwise, it is necessary to employ more complex direct experimental designs in order to ensure a constant resource level (Anholt 1990; Peckarsky 1991; Smallegange et al. 2006). To our knowledge, this strategy has only been applied to examine the effect of active interference in competitors foraging for large prey, where it is relatively easy to monitor their behavior and to maintain a stable prey density by immediately replacing each prey item eaten ("immediate consumption" approach). In comparison, there is a dearth of experimental studies examining the effect of passive interference between predator-harvesters, such as planktivorous fishes, which collect planktonic prey at the rate of 1 item every few seconds (Bartosiewicz and Gliwicz 2011).

Despite recent efforts to quantify the effects of interference (Gyimesi et al. 2010; Nakayama and Fuiman 2010; Rutten et al. 2010; Ping et al. 2011), little is known about how these effects are influenced by external factors that may be biotic (e.g., prey density) or abiotic (e.g., environmental temperature). Most previous studies-either theoretical (Stillman et al. 2000) or empirical (Sih 1981; Dolman 1995; Cresswell 1998; Triplet et al. 1999)—support the notion that interference is stronger at lower prey densities (or reduced encounter rates). This may be the result of either a prolonged search time during which interference can happen (Ruxton et al. 1992; Moody and Ruxton 1996) or the occurrence of an additional kind of interference that is profitable only when prey is sparse (e.g., kleptoparasitism in Stillman et al. 2002; aggression in Sale 1972). Since none of the aforementioned studies attempted to exclude the effect of exploitation, the impact of prey density on the effects of interference is yet to be fully investigated.

In ectotherms, the metabolic rate increases (exponentially) with temperature, leading to a greater energetic demand per individual that has to be compensated for by increasing assimilation (Aarssen 1983). A higher temperature enhances the ability of a predator to search for prey, due to (1) increased speed of movement (Persson 1986), (2) more effective prey-capture kinematics (Wintzer and Motta 2004), and (3) reduced handling time, which allows more time for searching (Thompson 1978). Greater foraging motivation and better searching ability may result in a higher encounter rate with the prey (Dreisig 1981), as well as an increased frequency of encounters with congeners or conspecifics (Kruse et al. 2008). The former may lead to higher capture rates, while the latter intensifies interference competition.

The importance of temperature in competitive interactions between foraging fish has mainly been studied in terms of the spatial or temporal separation of the fish, due to the different thermal optima of separate species (Baltz et al. 1982) or size classes within a single species (Beitinger and Magnuson 1975). Although the studies cited above have identified mechanisms that are responsible for stronger interactions at higher temperatures (usually increased aggressive behavior), the possible effects of other temperature-dependent components, such as exploitative competition, have generally been ignored. Consequently, the quantitative impact of interference remains unknown, because the effect of interference competition has not been separated from those of other possible factors. Despite the common belief that ambient temperature is crucial in determining the outcome of competitive interactions within a group of fish, and the abundance of literature on the temperature-dependent effects of competition in fish species from marine (Biro et al. 2010), riverine (Baltz et al. 1982; McMahon et al. 2007), and lacustrine (Beitinger and Magnuson 1975; Krause et al. 1998) environments, we are unaware of any study that has tested for such competitive interactions. Persson $(1982,1986)$ showed that the feeding activity of a common planktivorous fish (roach, Rutilus rutilus) increased with ambient temperature, and he suggested that this could alter the outcome of passive interference between individuals, but his claims lack experimental corroboration. 
The aim of this study was to assess the impact of passive interference competition on the prey capture rate of planktivorous fish by excluding the effect of exploitation competition. This was achieved by manipulation of the initial prey density and minute-by-minute addition of prey to maintain relatively constant average prey densities, irrespective of the number of foraging fish. This novel approach allowed us to determine whether, and to what extent, food concentration and temperature (the main factors controlling feeding rate and growth in fish; Wootton 1990) affect the strength of interference competition in roach.

\section{Materials and methods}

The experiments were performed during the summer (August 2009) and autumn (October 2009) periods at the Hydrobiological Station in Pilchy, Poland, within a field enclosure with mosquito netting walls and a transparent roof (Gliwicz et al. 2013). This setup ensured semi-natural conditions, including similar light intensities (1.7-3.8 $\mu \mathrm{m} \mathrm{m}^{-2} \mathrm{~s}^{-1} 30 \mathrm{~min}$ before dusk), with temperature being the only factor that differed significantly between the summer (19.4-20.2 $\left.{ }^{\circ} \mathrm{C}\right)$ and autumn (11.9-14.4 $\left.{ }^{\circ} \mathrm{C}\right)$ experiments. One-year-old $(8 \pm 1 \mathrm{~cm})$ roach (Rutilus rutilus) used in the experiments were caught in Lake Roś (Mazurian Lakes, NE Poland) using a standard trawl net at least 1 month before the start of the first experiment in each period. Post-capture, the experimental fish were maintained in 1000-L steel holding tanks (50 per tank) and fed daily with a constant amount of Daphnia prey (5000-10,000 per tank). The prey (Daphnia hyalina clone HG011 obtained from Lake Świecajty, Poland) was propagated in $10-\mathrm{L}$ aquaria at $20{ }^{\circ} \mathrm{C}$ and fed daily with the green alga Scenedesmus acutus at a concentration above the incipient food level $\left(1.0 \mathrm{mg} \mathrm{C} \mathrm{L}{ }^{-1}\right)$. The populations of both fish and prey were maintained in water from the epilimnion of Lake Roś that had been filtered through a 1- $\mu \mathrm{m}$ Millipore membrane filter. The Daphnia densities used in each experiment were similar to those commonly found in natural lakes (Lampert and Sommer 2007), and the roach density ranges were similar to those reported for fish feeding in shoals (e.g., Eklöv and Persson 1995; Gliwicz et al. 2006).

Seven short-lasting (5.5 min) experiments were performed in each period (August and October 2009) in opentopped, non-transparent PVC tanks containing $60 \mathrm{~L}$ of water. Each experiment employed 12 treatments: 1, 5, 10, or 20 fish were allowed to harvest Daphnia at one of three different density levels. In the first two experiments of each period (experiments without supplementation: $\mathrm{I}_{\text {nsuppl }}$ and $\mathrm{II}_{\text {nsuppl }}$ in the Appendix), initial Daphnia density levels of
5,10 , or 20 ind. $\mathrm{L}^{-1}$ were established but not subsequently replenished, so their exploitation by foraging fish caused a gradual decrease in prey density. These experiments were performed to determine the cumulative effect of interference and exploitation. In the subsequent experiments (experiments with supplementation: $\mathrm{I}_{\text {suppl }}-\mathrm{V}_{\text {suppl }}$ in the Appendix), the initial Daphnia densities were assessed and then maintained by minute-by-minute supplementation with numbers that were calculated to replace the eaten prey. Both the initial density and the supplement of Daphnia added each minute were specific to each treatment, and were determined (by trial and error) from the capture rate calculated from the two preceding experiments. The difference between the required and the realtime prey density (resulting from the difference between the rates of prey elimination and prey supplementation) increased over the course of each experiment due to the cumulative error, reaching its highest value at the end. Consequently, the difference between the mean (during the course of the experiment) and required (approximately 5, 10 , or 20 ind. $\mathrm{L}^{-1}$ ) density was always lower than the difference between the final (after 5.5 min of foraging) and required density. It was assumed that a difference of $10 \%$ between the required and final prey density is the threshold value below which the density could be considered stable and equal in treatments with the same required prey density level. This assumption was fulfilled only in the last three experiments of each period (main experiments: $\mathrm{III}_{\text {suppl}}{ }^{-}$ $\mathrm{V}_{\text {suppl }}$ ). Preliminary experiments with supplementation ( $\left.\mathrm{I}_{\text {suppl }}-\mathrm{II}_{\text {suppl }}\right)$ were excluded from the analysis.

Prior to the start of each experiment, the numbers of Daphnia required to establish the desired initial prey density in each treatment were placed in glass beakers containing $0.1 \mathrm{~L}$ of lake water. Another 60 beakers ( 5 for each treatment) containing $50 \mathrm{~mL}$ of filtered lake water only (experiments $\mathrm{I}_{\text {nsuppl }}-\mathrm{II}_{\text {nsuppl }}$ ) or water containing Daphnia (experiments $\mathrm{I}_{\text {suppl }}-\mathrm{V}_{\text {suppl }}$ ) were prepared, to be added at 1-min intervals during the experiment. The roach were netted from a holding tank, assigned to groups of the required size $(1,5,10$, or 20 fish), transferred into each experimental tank, and allowed sufficient time to acclimate to unconstrained foraging (based on previous experiments). The fish used in each experiment were netted at random from a group of $\sim 400$ individuals housed in eight separate 1000-L holding tanks, so the probability that the same fish were used in subsequent experiments in the same treatment was very low.

Each experiment began with the addition of a low initial prey density $\left(\sim 5\right.$ ind. $\left.\mathrm{L}^{-1}\right)$ to the first four tanks containing the required numbers of fish. A digital stopwatch was used to measure elapsed time, and the beakers containing filtered lake water only (in experiments $\mathrm{I}_{\text {nsuppl }}-\mathrm{II}_{\text {nsuppl }}$ ) or water with Daphnia (in experiments 
$\left.\mathrm{I}_{\text {suppl }}-\mathrm{V}_{\text {suppl }}\right)$ were emptied into the respective tanks at 60 -s intervals (after the 1st, 2nd, 3rd, 4th, and 5th minute). To ensure that the feeding fish did not suffer any external disturbance, prey additions were made via a plastic funnel connected to an angled glass tube passing through the wall of each tank and into the water. Continuous delicate bubble-induced mixing of the water was used to maintain a homogeneous distribution of prey items in the tanks. After 5.5 min of feeding, all fish were simultaneously removed from the tanks. This procedure was then repeated in 4 tanks with the intermediate $\left(\sim 10\right.$ ind. $\left.\mathrm{L}^{-1}\right)$ and finally with the high $\left(\sim 20\right.$ ind. $\left.\mathrm{L}^{-1}\right)$ density of Daphnia in such a way that the intervals between treatments were never longer than $5 \mathrm{~min}$. After removing the fish from the experimental tanks, all remaining Daphnia from each tank were collected separately using a zooplankton net. The Daphnia were immediately preserved in formaldehyde and concentrated in separate $200-\mathrm{mL}$ plastic containers for counting under a microscope.

In experiments $\mathrm{I}_{\text {nsuppl }}-\mathrm{II}_{\text {nsuppl }}$, the feeding rate of a fish $\left(C_{i}\right)$ in treatment $i$ was calculated simply as $C_{i}=\left(n_{0}-n_{\mathrm{t}}\right) \times N_{i}^{-1} \times \Delta t^{-1}$, where $n_{0}$ is the initial number of Daphnia (300, 600, or 1200 ind.), $n_{\mathrm{t}}$ the number of Daphnia remaining after the experiment, $N_{i}$ the number of fish $(1,5,10$, or 20 ind.), and $\Delta t$ the duration of the experiment $(5.5 \mathrm{~min})$. In experiments $\mathrm{I}_{\text {suppl }}-\mathrm{V}_{\text {suppl }}$, the initial prey density $\left(n_{\mathrm{i} 0}\right)$ was the sum of the required prey density assigned to each treatment $\left(n_{r}\right.$; i.e., 5,10 , or 20 Daphnia $\mathrm{L}^{-1}$ ) and the number of Daphnia equivalent to (and compensating for) the loss of prey items anticipated in the first $30 \mathrm{~s}$ of feeding $\left(C_{i x} \times N_{i} \times 2 V^{-1}\right)$, where $C_{i x}$ is the mean feeding rate in treatment $i$, as estimated from the two most recent previous experiments in the series, $N_{i}$ the number of fish in treatment $i$, and $V$ is the volume of water $(60 \mathrm{~L})$. Compensation for the anticipated reduction in prey abundance was achieved by the minute-by-minute addition of the calculated number of Daphnia $\left(C_{i x} \times N_{i}\right)$. The feeding rate of a fish $\left(C_{i}\right)$ in each treatment for experiments with supplementation $i$ was calculated as $C_{i}=\left(n_{i 0}+n \Delta t-n_{\mathrm{t}}\right) \times N_{i}^{-1} \times \Delta t^{-1}$, where $n \Delta t$ is the total number of Daphnia added each minute during the experiment.

The effects of the number of fish, Daphnia prey density, the presence or absence of prey supplementation each minute, and temperature on the capture rate of roach were tested in a general linear model, with the number of fish treated as a continuous variable and the other factors as categorical variables (SAS 9.4 procedure GLM; SAS Institute 2013). Due to interactions between fish number and both supplementation and temperature $\left(N_{\mathrm{f}} \times\right.$ Suppl and $N_{\mathrm{f}} \times$ Temp; Table 1; Fig. 1), four separate ANCOVAs (for the effects of Daphnia density, with $N_{\mathrm{f}}$ as a covariate)
Table 1 General linear model tests of effects on the prey capture rate of roach, with number of fish $\left(N_{\mathrm{f}}\right)$ employed as a continuous variable, and supplementation of prey at 1-min intervals (Suppl), temperature (Temp), and Daphnia prey density $\left(D_{\mathrm{p}}\right)$ as categorical variables

\begin{tabular}{lcrll}
\hline Factor or interaction & Mean square & \multicolumn{1}{l}{$F$} & df & $p$ \\
\hline$N_{\mathrm{f}}$ & 76.2 & 216.3 & 1 & $* * * *$ \\
Suppl & 0.0 & 0.0 & 1 & NS \\
Temp & 144.9 & 411.2 & 1 & $* * * *$ \\
$D_{\mathrm{p}}$ & 63.1 & 179.3 & 2 & $* * * *$ \\
$N_{\mathrm{f}} \times$ Suppl & 7.2 & 20.5 & 1 & $* * * *$ \\
$N_{\mathrm{f}} \times$ Temp & 17.3 & 49.0 & 1 & $* * * *$ \\
$N_{\mathrm{f}} \times \mathrm{D}_{\mathrm{p}}$ & 0.0 & 0.0 & 2 & NS \\
$D_{\mathrm{p}} \times$ Suppl & 1.2 & 3.3 & 2 & $*$ \\
$D_{\mathrm{p}} \times$ Temp & 11.0 & 31.4 & 2 & $* * * *$ \\
Suppl $\times$ Temp & 0.1 & 0.2 & 1 & NS \\
\hline
\end{tabular}

Data from experiments without supplementation $\left(\mathrm{I}_{\text {nsuppl }}-\mathrm{II}_{\text {nsuppl }}\right)$ and the main experiments with prey supplementation ( $\left.\mathrm{III}_{\text {suppl }}-\mathrm{V}_{\text {suppl }}\right)$

(1) Error degrees of freedom $=96, R^{2}=0.956$; (2) of all the higherorder interactions (not shown), only one was significant $\left(N_{\mathrm{f}} \times\right.$ Sup$\mathrm{pl} \times$ Temp, $p=0.03$ )

$N S$ not significant

Statistical significance: $* p<0.05, * * * * p<0.0001$

were performed for each combination of the two factors (SAS 9.4 procedure GLM; SAS Institute 2013). From these ANCOVAs, interval estimates were obtained for the effects of number of fish and Daphnia prey density, using Tukey's honest significant difference (HSD) method for unequal sample sizes, repeated for three standard significance levels (Table 2). The confidence level was set at $95 \%$, with the significance of each difference determined by comparing particular confidence limits (Cumming 2012).

\section{Results}

Only the results from the two experiments without supplementation ( $\mathrm{I}_{\text {nsuppl }}-\mathrm{II}_{\text {nsuppl }}$ in the Appendix) and the last three experiments of each series with prey supplementation (main experiments, $\mathrm{III}_{\text {suppl }}-\mathrm{V}_{\text {suppl }}$ in the Appendix) in each period (August and October) were included in the analysis. The difference between the initial and required mean prey density (i.e., 5, 10, or 20 Daphnia $\times \mathrm{L}^{-1}$ ) was maintained at less than $\pm 9 \%$, and the difference between the required final density (i.e., 5, 10, or 20 Daphnia $\times \mathrm{L}^{-1}$ ) and the obtained final prey density was kept below $\pm 10 \%$ for all treatments only in experiments $\mathrm{III}_{\text {suppl }}-\mathrm{V}_{\text {suppl }}$ (see the Appendix). In those experiments, the maximal number of Daphnia added to the tank each minute did not exceed $17 \%$ of the required mean density in a given treatment; therefore, the relative variation in prey density also did not exceed $17 \%$ in any treatment. 


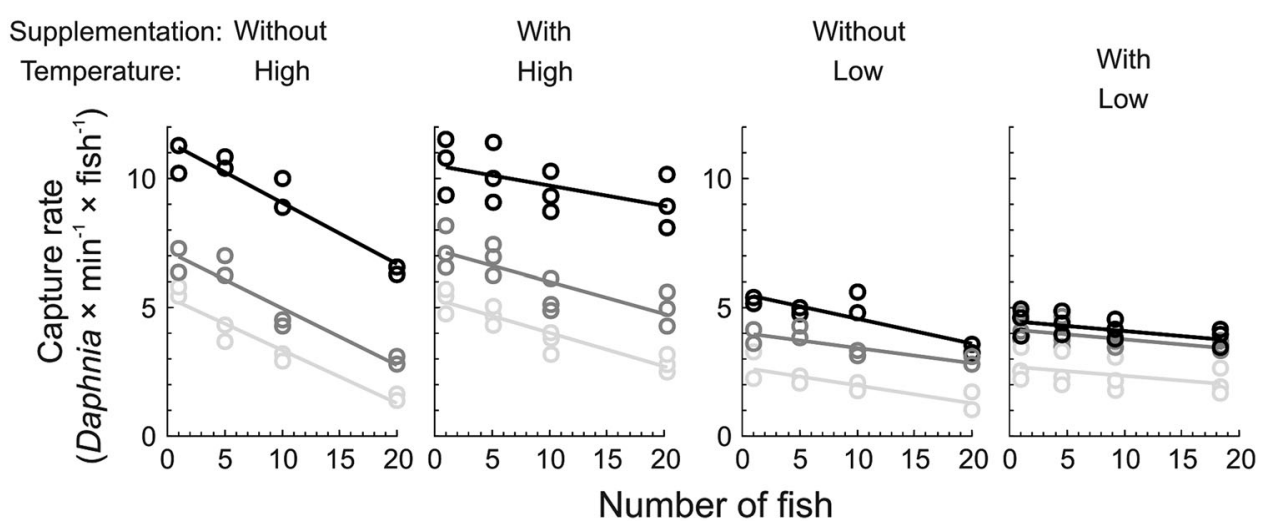

Fig. 1 Capture rates of fish foraging in different group sizes $(1,5,10$, or 20 roach) at three prey density levels $\left(5,10\right.$ or 20 Daphnia $\mathrm{L}^{-1}$; gray, dark gray, and black circles, each as a single treatment and regression lines, respectively) in two experiments without

supplementation of prey $\left(\mathrm{I}_{\text {nsuppl }}-\mathrm{II}_{\text {nsuppl }}\right)$ and in the main experiments with prey supplementation ( $\mathrm{III}_{\text {suppl }}-\mathrm{V}_{\text {suppl }}$ ), and at high and low ambient temperature

experiments without supplementation $\left(\mathrm{I}_{\text {nsuppl }}-\mathrm{II}_{\text {nsuppl }}\right)$ and the main experiments with prey supplementation ( $\mathrm{III}_{\text {suppl }}-\mathrm{V}_{\text {suppl }}$ ), and at high and low temperatures
Table 2 Effects of the number of fish $\left(N_{\mathrm{f}}\right.$, effect quantified by the slope of the relationship) and Daphnia prey density $\left(D_{\mathrm{p}}\right.$, differences between means in 5, 10, and 20 ind. $\mathrm{L}^{-1}$ treatments, denoted $\mathrm{d} 5, \mathrm{~d} 10$, and $\mathrm{d} 20$, respectively) on the prey capture rate of roach in

\begin{tabular}{lllll}
\hline $\begin{array}{l}\text { Suppl. } \\
\text { Temp. }\end{array}$ & Without & With & Without & Low \\
\hline$N_{\mathrm{f}}$ (slope) & $-0.22 * * *[-0.25,-0.19]$ & $-0.12 * * *[-0.15,-0.08]$ & $-0.08 * * *[-0.10,-0.05]$ & $\begin{array}{l}\text { With } \\
\text { Low }\end{array}$ \\
$D_{\mathrm{p}}(\mathrm{d} 20-\mathrm{d} 10)$ & $4.11 * * *[3.42,4.81]$ & $3.79 * * *[3.04,4.53]$ & $1.23 * * *[0.68,1.78]$ & $0.38 \mathrm{NS}[-0.07,-0.02]$ \\
$D_{\mathrm{p}}(\mathrm{d} 10-\mathrm{d} 5)$ & $1.64 * * *[0.94,2.34]$ & $2.03 * * *[1.29,2.78]$ & $1.53 * * *[0.98,2.08]$ & $1.63 * * *[1.13,2.13]$ \\
$D_{\mathrm{p}}(\mathrm{d} 20-\mathrm{d} 5)$ & $5.75 * * *[5.06,6.45]$ & $5.82 * * *[5.07,6.56]$ & $2.76 * * *[2.21,3.31]$ & $2.01 * * *[1.51,2.52]$ \\
\hline
\end{tabular}

The $95 \%$ confidence intervals are given in parentheses

$N S$ not significant

Statistical significance: $* p<0.05, * * * p<0.001$

The per capita feeding rate, calculated as the number of prey consumed per minute, was significantly affected by the number of fish, temperature, and Daphnia prey density, while there was no evidence for an overall effect of supplementation (Table 1). Analysis revealed that the effect of fish number (1) differed between experiments without supplementation and the main experiments with supplementation (Table 1, $N_{\mathrm{f}} \times$ Suppl. interaction), (2) was affected by temperature (Table $1, N_{\mathrm{f}} \times$ Temp interaction), but (3) showed no dependence on the density of Daphnia prey (Table 1 , nonsignificant $N_{\mathrm{f}} \times D_{\mathrm{p}}$ interaction). In further analyses performed separately for each supplementation $\times$ temperature combination, interactions between fish number and Daphnia density were consistently nonsignificant. The per capita feeding rate decreased as the number of foraging fish increased (all slopes were significantly negative; Table 2), and it was reduced at lower Daphnia prey densities. The effect of interference (effect of the $N_{\mathrm{f}}$ in expts. $\mathrm{III}_{\text {suppl }}-\mathrm{V}_{\text {suppl }}$ ) was greater at higher temperature (according to a comparison of the respective confidence limits in Table 2). In particular, the differences in capture rates between Daphnia densities were much more apparent at higher temperature (Table 2).

\section{Discussion}

The experiments performed in this study were designed to separate the effect of exploitative competition from the effect of interference in a planktivorous fish (roach)-zooplankton (Daphnia) system, in order to determine whether the latter phenomenon causes a reduction in capture rate. To achieve this, a relatively stable prey density was maintained, regardless of the number of foraging fish in the experimental tanks, by supplementation to replace eliminated prey at constant and reasonably short intervals. The obtained data indicate that a typical planktivorous fish such as roach may suffer from reduced foraging efficiency, not only due to ongoing exploitation, but also as a result of direct interactions within the shoal. As it was not possible to quantify the effects of antagonistic interactions, the mechanisms underlying the competitive behavior 
responsible for this reduction remain uncharacterized. Nevertheless, since antagonistic behavior is commonly regarded as rare or even absent in young roach (Haberlehner 1988), we speculate that this effect is not due to aggressive interactions. Conceivably, the most important mechanism involves passive interference, where individuals obstruct access to resources due to non-aggressive behavior, e.g., encounter avoidance.

The reduction in foraging efficiency could also be due (at least in part) to the time lag when multiple fish attempt to capture a single prey item and all but one are unsuccessful. However, this is likely to have been of minor importance in our experiments because, unlike in the "immediate consumption" approach, the visual field of each fish was continuously filled with tiny prey items. Conversely, two other effects of grouping may enhance foraging success (Davis and Olla 1992). First, there is a stronger urge to feed, since fish tend to capture the subsequent prey as fast as possible before it is taken by a nearby competitor (Pitcher et al. 1982). Second, there is the opportunity to invest more time in capturing prey, since the task of vigilance can be shared among group members (Roberts 1996; Bartosiewicz and Gliwicz 2011). Nevertheless, the decline in capture rate detected in fish in a larger group implies that overall deterioration of foraging conditions due to encounter avoidance and the increased probability of unsuccessful attack far outweighs any potential benefits of grouping in the conducted experiments.

The experimental method employed here is different from any used in previous studies, in which two kinds of competition were separated (Anholt 1990; Smallegange et al. 2006). Our novel approach was considered most suitable because the high capture rates of planktivorous fish feeding on zooplankton necessitated supplementation with high numbers of tiny Daphnia (up to 218 individuals every minute for the treatment with the highest prey and fish densities). This particular feature of the planktivorous fishzooplankton interface prevented the use of the immediate consumption approach employed previously to test the effect of interference on fish feeding exclusively on relatively large food items such as cold-killed adult Artemia salina (Rangeley and Kramer 1998) or artificial food (Shaw et al. 1995). The specificity of the planktivorous fishzooplankton interface made it possible to (1) conduct shorter experiments than those performed with less-voracious predators, e.g., damselfly larvae (Anholt 1990), and (2) use a prey supplementation method based on the provision of previously calculated prey numbers at 1-min intervals. In a previous study (Bartosiewicz and Gliwicz 2011), the instant replacement of each prey eaten proved challenging in the case of three simultaneously foraging fish consuming up to one prey per second, and so would not be feasible for 10 or 20 foraging fish. The minute-byminute supplementation of Daphnia did not preclude variations in their density from higher (just after a supplementation) to lower (just before the subsequent supplementation) than required, particularly in treatments with the highest fish density. Nevertheless, it is reasonable to assume that a decreased capture rate towards the end of each minute was compensated for by an increased capture rate at the start of the next minute, so that these effects canceled each other out.

The findings of this study support the notion that capture rates in planktivorous fish increase at higher prey densities (e.g., Eggers 1977; Gliwicz et al. 2013). The results did not reveal any difference in the strength of interference at different prey density levels, even though it might be expected that interference would be stronger at low prey densities when fish swim faster in an attempt to compensate for a lower prey encounter rate (Munk and Kiørboe 1985, Maszczyk and Gliwicz 2014). The effect of higher swimming speed could be even more pronounced in a spatially large-scale system with heterogeneously distributed prey, where fish are able to swim with appropriate speed. In this scenario, the increased speed of fish in a less profitable patch reflects the need to compensate for a low encounter rate and the need to rapidly locate a more profitable patch. However, in such a system, prey density dependent interference may be more affected by the presence of a larger number of fish within a more profitable patch due to their swift numerical response than by changes in swimming speed. If this is the case, then in systems where foraging is less spatially constrained and conditions are closer to the open and diverse reality of a lake, it is more likely that interference becomes stronger at high rather than low prey density. The results of this study also show that the foraging rate and the effect of interference competition are greater at higher temperature, thus leading to a need for supplementation with a greater number of prey and slightly larger fluctuations in the actual prey density within each 1-min interval during the experiments.

In conclusion, the results of this study indicate that the effect of interference competition on the feeding rates of planktivorous fish in groups of different sizes can be assessed when separated from that of exploitation through the maintenance of a stable prey density. Using such a methodological approach, we have demonstrated that the strength of interference competition may vary with environmental conditions.

Acknowledgments We thank Z.M. Gliwicz, J.R. Gittins, and B.D. Barst for their insightful comments that have improved the manuscript, P. Koperski for statistical support, as well as J. Dziarska-Pałac, A. Hankiewicz, M. Kulik, and M. Nowicka for assistance during the experiments. This research was supported by a grant from the State Committee for Scientific Research, Poland (NN304 067336) to P. 
Maszczyk, as well as grant 2011/03/B/NZ8/02093 from the Polish National Science Center to Z.M. Gliwicz. The final part of this study was carried out at the Biological and Chemical Research Centre, University of Warsaw, established within a project co-financed by the EU European Regional Development Fund under the Innovative Economy Operational Program, 2007-2013. All experiments comply with the current laws of the country in which they were performed.

Open Access This article is distributed under the terms of the Creative Commons Attribution License which permits any use, distribution, and reproduction in any medium, provided the original author(s) and the source are credited.

\section{References}

Aarssen LW (1983) Ecological combining ability and competitive combining ability in plants: toward a general evolutionary theory of coexistence in systems of competition. Am Nat 122:707-731

Anholt BR (1990) An experimental separation of interference and exploitative competition in a larval damselfly. Ecology 71:1483-1493

Baltz DM, Moyle PB, Knight NJ (1982) Competitive interactions between benthic stream fishes, riffle sculpin (Cottus gulosus) and speckled dace (Rhinichthys osculus). Can J Fish Aquat Sci 39:1502-1511

Bartosiewicz M, Gliwicz ZM (2011) Temporary intermissions in capturing prey (Daphnia) by planktivorous fish (Rutilus rutilus): are they due to scramble competition or the need for antipredation vigilance? Hydrobiologia 668:125-136

Beitinger TL, Magnuson JJ (1975) Influence of social rank and size on thermoselection behavior of bluegill (Lepomis macrochirus). J Fish Res Board Can 32:2133-2136

Biro PA, Beckmann C, Stamps JA (2010) Small within-day increases in temperature affects boldness and alters personality in coral reef fish. Proc R Soc Lond Biol 277:71-77

Cresswell W (1997) Interference competition at low competitor densities in blackbirds Turdus merula. J Anim Ecol 66:461-471

Cresswell W (1998) Variation in the strength of interference competition with resource density in blackbirds, Turdus merula. Oikos 81:152-160

Cumming G (2012) Understanding the new statistics. Routledge, New York

Davis MW, Olla BL (1992) The role of visual cues in the facilitation of growth in a schooling fish. Environ Biol Fishes 34:421-424

Dolman PM (1995) The intensity of interference varies with resource density: evidence from a field study with snow buntings Plectrophenox nivalis. Oecologia 102:511-514

Dreisig H (1981) The rate of predation and its temperature dependence in a tiger beetle Cicindela hybrids. Oikos 36:196-202

Eggers DM (1977) The nature of prey selection by planktivorous fish. Ecology 58:46-59

Eklöv P, Persson L (1995) Species-specific antipredator capacities and prey refuges: interactions between piscivorous perch (Perca fluviatilis) and juvenile perch and roach (Rutilus rutilus). Behav Ecol Sociobiol 37:169-178

Ens BJ, Goss-Custard JD (1984) Interference among oystercatchers, Haematopus ostralegus, feeding on mussels, Mytilus edulis, on the Exe estuary. J Anim Ecol 53:217-231

Folt C, Goldman CR (1981) Allelopathy between zoo-plankton: a mechanism for interference competition. Science 213:1133-1135
Gliwicz ZM, Slon J, Szynkarczyk I (2006) Trading safety for food: gut contents in roach and bleak captured at different distances offshore from their daytime littoral refuge. Freshwat Biol 51:823-839

Gliwicz ZM, Maszczyk P, Jabłoński J, Wrzosek D (2013) Patch exploitation by planktivorous fish and the concept of aggregation as an antipredation defense in zooplankton. Limnol Oceanogr 58:1621-1639

Gyimesi A, Stillman RA, Nolet BA (2010) Cryptic interference competition in swans foraging on cryptic prey. Anim Behav 80:791-797

Haberlehner E (1988) Comparative analysis of feeding and schooling behaviour of the Cyprinidae Alburnus alburnus (L. 1758), Rutilus rutilus (L. 1758), and Scardinius erythrophthalamus (L. 1758) in a backwater of the Danube near Vienna. Int Rev Hydrobiologia 73:537-546

Hassell MP, Varley GC (1969) New inductive population model for insect parasites and its bearing on biological control. Nature 223:1133-1136

Krause J, Staaks G, Mehner T (1998) Habitat choice in shoal of roach as a function of water temperature and feeding rate. J Fish Biol 53:377-386

Kruse PD, Toft S, Sunderland KD (2008) Temperature and prey capture: opposite relationships in two predator taxa. Ecol Entomol 33:305-312

Lampert W, Sommer U (2007) Limnoecology: the ecology of lakes and streams, 2nd edn. Oxford University Press, New York, pp 234-277

MacIsaac HJ, Gilbert JJ (1991) Discrimination between exploitative and interference competition between Keratella cochlearis and Cladocera. Ecology 72:924-937

Mansour RA, Lipcius RN (1991) Density-dependent foraging and mutual interference in blue crabs preying upon infaunal clams. Mar Ecol Prog Ser 72:239-246

Maszczyk P, Gliwicz ZM (2014) Selectivity by planktivorous fish at different prey densities, heterogeneities, and spatial scales. Limnol Oceanogr 59:68-78

McMahon TE, Zale AV, Barrows FT, Selong J, Danehy R (2007) Temperature and competition between bull trout and brook trout: a test of the elevation refuge hypothesis. Trans Am Fish Soc 136:1313-1326

Miller RS (1967) Pattern and process in competition. Adv Ecol Res 4:1-74

Moody AL, Ruxton GD (1996) The intensity of interference varies with food density: support for behaviour-based models of interference. Oecologia 108:446-449

Munk P, Kiørboe T (1985) Feeding behavior and swimming activity of larval herring Clupea harengus in relation to density of copepod nauplii. Mar Ecol Prog Ser 24:15-21

Nakayama S, Fuiman LA (2010) Body size and vigilance mediate asymmetric interference competition for food in fish larvae. Behav Ecol 21:708-713

Peckarsky BL (1991) Mechanisms of intra- and interspecific interference between larval stoneflies. Oecologia 85:521-529

Persson L (1982) Rate of food evacuation in roach (Rutilus rutilus) in relation to temperature, and the application of evacuation rate estimates for studies on the rate of food consumption. Freshwat Biol 12:203-210

Persson L (1986) Temperature-induced shift in foraging ability in two fish species, roach (Rutilus rutilus) and perch (Perca fluviutilis): implications for coexistence between poikilotherms. J Anim Ecol 55:829-939

Ping X, Li C, Jiang Z, Liu W, Zhu H (2011) Interference competition and group size effect in sika deer (Cervus nippon) at salt licks. Acta Ethol 14:43-49 
Pitcher TJ, Magurran AE, Winfield IJ (1982) Fish in larger shoals find food faster. Behav Ecol Sociobiol 10:149-151

Post JR, Parkinson EA, Johnston NT (1999) Density-dependent processes in structured fish populations: interaction strengths in whole-lake experiments. Ecol Monogr 69:155-175

Rangeley RW, Kramer DL (1998) Density-dependent antipredation tactics and habitat selection in juvenile pollock. Ecology 79:943-952

Roberts G (1996) Why individual vigilance declines as group size increases. Anim Behav 51:1077-1086

Rutten AL, Oosterbeek K, van der Meer J, Verhulst S, Ens BJ (2010) Experimental evidence for interference competition in oystercatchers, Haematopus ostralegus. I. Captive birds. Behav Ecol 21:1251-1260

Ruxton GD, Gurney WSC, de Roos AM (1992) Interference and generation cycles. Theor Popul Biol 42:235-253

Sale PF (1972) Effect of cover on agonistic behavior of a reef fish: a possible spacing mechanism. Ecology 53:753-758

SAS Institute Inc. (2013) SAS/STAT ${ }^{\circledR} 12.3$ user's guide. SAS Institute Inc., Cary

Scharf I, Filin I, Ovadia O (2008) An experimental design and a statistical analysis separating interference from exploitation competition. Popul Ecol 50:319-324

Schoener TW (1983) Field experiments on interspecific competition. Am Nat 122:240-285

Shaw J, Tregenza T, Parker GA, Harvey IF (1995) Evolutionarily stable foraging speeds in feeding scrambles: a model and an experimental test. Proc R Soc Lond Biol 260:273-277

Sih A (1981) Stability, prey density and age-dependent interference in an aquatic insect predator, Notonecta hoffmanni. J Anim Ecol $50: 625-636$
Smallegange IM, Van der Meer RH, Kurvers JM (2006) Disentangling interference competition from exploitative competition in a crab-bivalve system using a novel experimental approach. Oikos 113:157-167

Steinwascher K (1978) Interference and exploitation competition among tadpoles of Rana utricularia. Ecology 59:1039-1046

Stillman RA, Goss-Custard JD, Alexander MJ (2000) Predator search pattern and the strength of interference through prey depression. Behav Ecol 11:597-605

Stillman RA, Poole AE, Goss-Custard JD, Caldow RWG, Yates MG, Triplet P (2002) Predicting the strength of interference more quickly using behaviour-based models. J Anim Ecol 71:532-541

Sutherland WJ, Koene P (1982) Field estimates of the strength of interference between oystercatchers Haematopus ostralegus. Oecologia 55:108-109

Thompson DJ (1978) Towards a realistic predator-prey model: the effect of temperature on the functional response and life history of larvae of the damselfly, Ischnura elegans. J Anim Ecol 47:757-767

Triplet P, Stillman RA, Goss-Custard JD (1999) Prey abundance and the strength of interference in a foraging shorebird. J Anim Ecol 68:254-265

Vahl WK, van der Meer J, Weissing FJ, van Dullemen D, Piersma T (2005) The mechanisms of interference competition: two experiments on foraging waders. Behav Ecol 16:845-855

Wintzer AP, Motta PJ (2004) The effects of temperature on prey capture kinematics of bluegill (Lepomis macrochirus): implications for feeding studies. Can J Zool 82:794-799

Wootton RJ (1990) Ecology of teleost fishes. Kluwer, Dordrecht 